\title{
Current situation of mechanical CPR devices in donors after cardiac death
}

\author{
Alonso A. Mateos Rodríguez ${ }^{1^{*}}$, José María Navalpotro Pascual ${ }^{1}$, \\ Vicnete Sanchez Brunete Ingelmo ${ }^{1}$, Francesc Carmona Jiménez ${ }^{2}$ \\ ${ }^{1}$ Servicio de Urgencias Médicas de Madrid SUMMA112 (Emergency Medical Services of Madrid), Madrid, Spain; \\ *Corresponding Author: amateos.summa@salud.madrid.org \\ ${ }^{2}$ Servei Emergencies Mediques (Emergency Medical Services), Barcelona, Spain
}

Received 17 October 2013; revised 19 November 2013; accepted 5 December 2013

Copyright (C) 2013 Alonso A. Mateos Rodríguez et al. This is an open access article distributed under the Creative Commons Attribution License, which permits unrestricted use, distribution, and reproduction in any medium, provided the original work is properly cited. In accordance of the Creative Commons Attribution License all Copyrights (C) 2013 are reserved for SCIRP and the owner of the intellectual property Alonso A. Mateos Rodríguez et al. All Copyright (c) 2013 are guarded by law and by SCIRP as a guardian.

\begin{abstract}
Mechanical CPR (cardiopulmonary resuscitation) devices help performing correct chest compressions in the event of a cardiorespiratory arrest. These devices are comfortable and useful, they keep chest compression following the recommendations as they do not depend on interpersonal variability, they do not get tired, their use is simple and one of the rescuers is released from this task, thus facilitating the assistance. Besides, their use in transport conditions makes it safer. However, when coming to results, these mechanical CPR devices have not clearly demonstrated such an advantage, neither in the field of cardiac arrest, nor in organ preservation in the case of donors after cardiac death. In donors after cardiac death they are widely used by most of the emergency services involved, but a number of injuries produced in lungs during the early years of their use have made it controversial. In this paper we make a review of the road traveled by mechanical CPR devices and of the main articles which mark the way.
\end{abstract}

Keywords: Emergency Medical Services; Donors after Cardiac Death; Cardiocompressors

\section{INTRODUCTION}

In the last few years, several mechanical devices have been developed to replace manual cardiac massage in the event of a cardiorespiratory arrest. These devices have shown to improve quality of cardiopulmonary resuscitation [1] and, in some cases, an improvement of short- term survival has been proven [2,3]. Two devices are currently being used: LUCAS $^{\odot}$, Lung University Cardiac Arrest System, from the company Physio-Control, and Autopulse $^{\odot}$, from Zoll. There is a third device in the market from the company Corpuls based on a piston-arm with a base recalling the old devices, but improved.

LUCAS $^{\odot}$ is a piston system with a suction cup which attaches the patient chest in a specific point. By means of oxygen or compressed air in version 1 and rechargeable batteries in version 2, it exerts pressure up and down. Autopulse $^{\odot}$ exerts the same pressure on the chest, but does so by means of a load distribution band which embraces the patient trunk, and uses rechargeable batteries. Both devices have two possibilities for performing chest compressions: rhythm 30:2 or continuous massage, and they present as an additional advantage the fact that one of the rescuers involved in resuscitation is released from this task. Their use and placement are very simple. They are widely used by most of the emergency services in cardiopulmonary arrest cases and in organ donation in asystole [4]. Due to its cost it is complicated for these devices to be shipped with the whole fleet of mobile resources, therefore, most emergency services carry them on a special vehicle featured in the scene at the request of the professionals. Their primary use is intended for the return of spontaneous circulation, and if this is not achieved, devices are used for the transfer of the potential donor if this is the case.

In Spain, the Organización Nacional de Trasplantes (National Transplant Organization), in its consensus document for promoting donors after cardiac death, recommends the use of these devices as a way of implementing programs of donation in asystole. At European level, a document is being drafted in the same direction of the Spanish one recommending their use as well [5]. 
Many studies have been published referring to the possible injuries that mechanical CPR devices could cause to patients. Smekal et al. already proved that injuries produced by these devices were similar to those found on cases of manual chest compression [6]. However, in spite of studies like this, the reputation of the mechanical CPR devices was determined on the side of injuries. In this review we want to debunk this myth on the basis of several articles published in the last few years.

\section{MECHANICAL CPR DEVICES IN CARDIORESPIRATORY ARREST}

Mechanical CPR devices have not yet demonstrated a clear return of spontaneous circulation. There are two studies which are working on this objective in a randomized way. CIRC Trial studies the Autopulse ${ }^{\complement}$, and in preliminary data it has proven to have the same rate of survival to hospital discharge than high-quality manual massage. The problem is, who can achieve this high-quality manual massage for an extended time [7]. So does LINC Trial with LUCAS $^{\circledR}$, the LINC study showed similar short-term survival rates for LUCAS (23.6\%) and manual $(23.7 \%)$ chest compressions. At 6-months, $8.5 \%$ of the patients treated with LUCAS were alive with good neurological outcomes compared to $7.6 \%$ in the manual group [8].

Despite not having shown a clear improvement in ROSC [9] (return of spontaneous circulation) or in survival to hospital discharge, they make it when it comes to optimum fulfillment of protocols $[10,11]$ and safety in cardiopulmonary resuscitation [12,13]. Only these two aspects, on equal terms with manual chest compression, already justify their use.

\section{MECHANICAL CPR DEVICES AS A PRESERVATION METHOD FOR THE DONORS AFTER CARDIAC DEATH}

In 2010 we published an article where we evaluated the efficiency of CPR devices as an organ preservation method [14]. We compared two groups of donors after cardiac death of approximately 40 cases each; one group was assisted with CPR devices and the other one with manual chest compression. The rate of kidneys and the rate of organs and tissues per donor were significantly lower in the group of donors assisted with mechanical CPR devices. These data made us wonder if the use of these devices was correct, and we started to study them further.

\section{CPR DEVICES IN KIDNEY GRAFTS}

The limits of our study were clear, since we collected just a few cases and we only evaluated transplanted organs without considering their evolution thereafter. In detail, and if we just evaluate kidney grafts, data offered by a group of donors assisted with CPR devices vs manual cardiac massage are almost the same. The cases of primary graft failure were similar in both groups and present a very low frequency, around 8\% [15]. Later, it has been observed that long-term function of kidney grafts is very similar in both groups of patients. Data from a cohort of 50 other donors divided into CPR devices and non-CPR devices reveal that, after 6 and 12 months, the renal function (creatinine) was somewhat higher in the group assisted with CPR devices, but not reaching pathological levels and without being statistically significant [16]. In a similar study, in which LU$\mathrm{CAS}^{\odot}$ was evaluated, results marked a clear advantage in favour of CPR devices [17], objectifying an improvement of 0.3 kidneys transplanted per donor in the CPR devices group and a decrease of $32.9 \%$ of kidney grafts discarded because of poor perfusion. It seems proved that CPR devices do not affect further evolution of kidney grafts, actually, they may even improve it.

\section{CPR DEVICES IN LUNG GRAFTS}

As a matter of fact, injuries produced by CPR devices usually appeared in lungs, as it can be easily understood because of the pressure exerted over them during cardiopulmonary resuscitation. These injuries have been commented many times, but never published. Numerous articles have appeared objectifying the presence of traumatic injuries on the chest and lungs of patients assisted with mechanical CPR devices, and in all of them results are similar: there is no significant difference between injuries produced by manual chest compression and those caused by mechanical devices [6,18-20]. Even in a number of lungs evaluated for transplantation from patients which had been assisted with CPR devices, major injuries were not noticed, or at least, not that major injuries as to discard the lungs for transplantation. In patients considered as donors 8 pathological bronchoscopes were objectified, 3 of them with bronchial aspiration and 5 with blood-borne secretions; no rib fractures were noticed but there appeared 2 cases of sternal fracture. Injuries were never described as serious, and they were never a potential reason for discarding the organ for transplantation. This kind of lung grafts presents a highly satisfactory evolution thereafter. Out of 20 patients receiving lungs from donors after cardiac death, 18 survived the first month [21]. Most of these lungs had been subjected to CPR devices.

\section{CONCLUSION}

Even though it seems that at first mechanical CPR devices had been associated with the presence of injuries in organs of patients assisted with them, and that their use 
in donor processes seemed to decrease the number of suitable organs, these data have not been confirmed by further investigations. While it is true that in few occasions have they shown an improvement compared to manual chest compression, the advantages that they offer make their use generalized and unquestionable. Further studies with a larger number of populations are needed to know in detail the results of these mechanical CPR devices in organs which are candidates to be transplanted.

\section{REFERENCES}

[1] Nielsen, N., Sandhall, L., Schersten, F., Friberg, H. and Olsson, S.E. (2005) Successful resuscitation with mechanical CPR, therapeutic hypothermia and coronary intervention during manual CPR after out-of-hospital cardiac arrest. Resuscitation, 65, 111-113.

http://dx.doi.org/10.1016/j.resuscitation.2004.11.007

[2] Casner, M., Anderson, D., et al. (2005) Preliminary report of the impact of a new CPR assist device on the rate of return of spontaneous circulation in out of hospital cardiac arrest. Pre-Hospital Emergency Medicine, 9, 61-67. http://dx.doi.org/10.1080/10903120590891714

[3] Steen, S., Liao, Q., Pierre, L., Paskevicius, A. and Sjoberg, T. (2002) Evaluation of LUCAS, a new device for automatic mechanical compression and active decompression resuscitation. Resuscitation, 55, 285-599. http://dx.doi.org/10.1016/S0300-9572(02)00271-X

[4] (2012) Consent document for asystole donors in Spain. Organización Nacional de Trasplantes.

[5] ESOT (2013) 6th International Conference Donors after Cardiac Death. European Society for Organ Transplantation, Paris.

[6] Smekal, D., Johansson, J., Huzevka, T. and Rubertsson, S. (2009) No difference in autopsy detected injuries in cardiac arrest patients treated with manual chest compressions compared with mechanical compressions with the LUCAS $^{\mathrm{TM}}$ device-A pilot study. Resuscitation, 80, 1104-1107.

http://dx.doi.org/10.1016/j.resuscitation.2009.06.010

[7] (2012) CIRC trial. European Resuscitation Council Congress, Vienna.

[8] (2103) LINC trail. Oral comunication. European Cardiology Congress, Amsterdam.

[9] Ballesteros Peña, S. (2013) Survival after prehospital cardiac arrest in Spain: A review of the literature. Emergencias, 25, 137-142.

[10] Wigginton, J.G., Isaacs, S.M. and Kay, J.J. (2007) Mechanical devices for cardiopulmonary resuscitation. Current Opinion in Critical Care, 13, 273-279. http://dx.doi.org/10.1097/MCC.0b013e328155d4ab

[11] Carmona Jiménez, F., Palma Padró, P., Soto García, M.A. and Rodríguez Venegas, J.C. (2012) Cerebral blood flow measured by transcranial doppler ultrasound during manual chest wall or automated LUCAS-2 compressions during cardiopulmonary resuscitation. Emergencias, 24, 47-49.

[12] Olasveengen, T.M., Wik, L. and Steen, P.A. (2008) Quality of cardiopulmonary resuscitation before and during transport in out-of-hospital cardiac arrest. Resuscitation, 76, 970-976.

http://dx.doi.org/10.1016/j.resuscitation.2007.07.001

[13] Camacho Leis, C., Almagro González, V., De Elías Hernández, R., Esquilas Sánchez, O., Moreno Martín, J.L., Muñoz Hermosa, E.J., et al. (2013) Feedback on chest compression quality variables and their relationship to rate of return of spontaneous circulation. Emergencias, 25, 99-104.

[14] Mateos Rodríguez, A.A., Navalpotro Pascual, M.J., Martín Maldonado, M.E., Barba Alonso, C., Pardillos Ferrer, L. and Andrés Belmonte, A. (2010) Mechanical cardiopump use in organ donation after prehospital cardiac death, Emergencias, 22, 264-268.

[15] Mateos-Rodriguez, Navalpotro-Pascual, J.M., PardillosFerrer, L. and Martin-Maldonado (2010) Cardiac life mechanical support in extrahospitalary donors after cardiac dead. Resuscitation, 81, 904-905. http://dx.doi.org/10.1016/j.resuscitation.2010.09.260

[16] Mateos-Rodríguez, A.A., Navalpotro-Pascual, J.M. and Andres-Belmonte, A. (2013) Donor after cardiac death kidney graft under mechanical cardiac compression evolution. Resuscitation, 84, 117-119.

http://dx.doi.org/10.1016/j.resuscitation.2013.04.021

[17] Carmona Jiménez, F., Ruiz Arránz, A., Palma Padró, P., Soto García, A., Alberola Martín, M. and Saavedra Escobar, S. (2012) Use of the Lucas mechanical chest compression device in an asystolic organ donation program: effect on kidney perfusion and organ procurement and transplantation rate. Emergencias, 24, 366-371.

[18] Menzies, D., et al. (2010) Does the LUCAS device result in increased injury during CPR? Resuscitation, 81, S20. http://dx.doi.org/10.1016/j.resuscitation.2010.09.092

[19] Xanthos, T., et al. (2010) A comparison of autopsy detected injuries in a porcine model of cardiac arrest treated with either manual or mechanical chest compressions. European Journal of Emergency Medicine, in Press.

[20] Englund, E., et al. (2008) Injuries after cardiopulmonary resuscitation: A comparison between LUCAS mechanical CPR and standard CPR. Resuscitation, 77, AS-036. http://dx.doi.org/10.1016/j.resuscitation.2008.03.050

[21] Rodríguez, A.A.M., Pascual, J.M.N. and del Río Gallegos, F. (2013) Lung transplant of extrahospitalary donor after cardiac death. The American Journal of Emergency Medicine, 31, 710-711. http://dx.doi.org/10.1016/j.ajem.2012.10.034 